\title{
Local Economic and Environmental Changes Associated with Plastic Ban Policy Implementation
}

\author{
David Harold Q. Pacatang
}

\begin{abstract}
The pervasive use of plastic raises major environmental concerns about the adverse effects on ecosystems as well as the economy, which impacts both consumers and vendors. To address the issue, in 2013 the local government unit of Dipolog City passed Ordinance No. 13-245 to regulate the sale, distribution, or use of non-compostable plastic bags including Styrofoam products, thus limiting the use of plastic. The regulation was an effort to take preventive measures to achieve a healthier environment. This study was conducted to find out how residents perceived the effects of the ordinance on both the environment and the economy. Specifically, this study was guided by the following objectives: 1.) identify consumer and vendor behaviors affected by the ordinances; 2.) determine residents' perception of the effects of the plastic-bag bans; and 3.) compare the effects of the ban on the environment with the effects on the economy based on significant differences in the profile of the participants of the study. Of the 100 participants, moderate effects on the environment were noted. Effects on the economy were also noted but varied by location of participants.
\end{abstract}

Keywords: environmental ordinance; plastic-bag ban; plastic ban

\section{Introduction}

Plastics are not biodegradable and end up either in landfills or as litter on the land and in waterways, including the ocean. Plastic can take hundreds of years to decompose ${ }^{1}$ and while it does so, the process releases toxins into the soil and water. ${ }^{2}$ To counter this problem, at least 27 cities in the Philippines banned the use of plastic bags after the national Philippine Ecological Solid Waste Management Act of 2000, by passing ordinances that prohibit the sale, distribution, and use of plastic bags as primary and secondary packaging materials for dry goods and as secondary packaging materials for wet goods.
Dipolog City was one of the cities to follow suit after the enactment of the Solid Waste Management Act in 2000.

Located in the western part of the Mindanao islands of the Philippines, Dipolog's major sources of livelihood lie in construction, fishing, agriculture and services. A city with a total population of $120,000,{ }^{3}$ the people were assumed to use plastic bags for every purchase in stores, supermarkets, malls, shopping centers, markets, and other commercial entities. Hence, the city government enacted Ordinance No. 13-245 in 2013 as "No Plastic Day"4 on Fridays and strictly enforced its implementation. This ordinance was in line with another local ordinance on sanitation and cleanliness known as Ordinance No. 123, which is Garbage Collection and Environmental Health Protection and Sanitation Code of 1998 for the City of Dipolog.

The local plastic bag regulation ordinance, No Plastic Day on Friday, and Ordinance No. 123 on sanitation and cleanliness were designed to regulate the use of plastic bags in an effort to improve the cleanliness and sanitation in Dipolog City and to sustain a healthy ecosystem. The effects of these regulations can be observed every Friday at the Dipolog City central public market, as well as at flea markets and the bus terminal. No Plastic Day has also been 
imposed during tabo, or market day, which is held every Friday and Saturday. ${ }^{4}$ By and large, both sellers and buyers have been complying with the law. Most vendors are now using paper bags and fish vendors use banana leaves or netbags to wrap the fish for consumers. In addition, customers now bring their own baskets, bags, and containers; both producers and consumers seem to be giving their full support and cooperation. ${ }^{5}$

The plastic-bag bans were implemented between 2013 and 2014. In the first quarter of 2015, 191 new businesses were registered in Dipolog City. ${ }^{6}$ As some of these establishments offered products that used plastics for wrapping, this suggested room for improvement in the ban's affect on new business.

The Republic Act No. 9003, another name for the Philippine Ecological Solid Waste Management Act of 2000, mandates the creation of solid waste management schemes to preserve and protect human ecological systems. The regulation also stipulates that information on waste collection services, solid waste management, and related health and environmental concerns be widely disseminated among the public either through print and broadcast media or other government agencies.

This is supported with an interview conducted on April 5, 2017 by the author, with Rodney Benedicto, Head of CENRO and Ariel Saldariega of Environmental Sanitation Office, both of Dipolog City, and both stated that the ordinance is largely based on information dissemination as reduction of solid wastes can hardly be measured. Accordingly, Carroll ${ }^{7}$ argues that by improving the ecology system, it will save a lot of expenditure on pollution control, enhancing public awareness of environmental protection and corporate social responsibility. De Leon ${ }^{8}$ also stressed that the people play an important role in ensuring that the environment is apt to support life.

\section{Research Design and Methods}

This study used a descriptive survey in the form of a two-part questionnaire and an unstructured interview to clarify the questionnaire responses. Part I, a checklist, and Part II, a survey, were extracted from the study of Thompson et al. ${ }^{9}$ and the text of another local ordinance, Ordinance 123. Percentage computation, ranking, weighted mean, and Wilcoxon Signed Rank Test were the main statistical tools used in the study.

The study participants comprised 100 individuals-50 consumers and 50 vendors who had to meet several requirements and fit a specific profile. Since these individuals were selected to represent a sample of the relevant population, quota sampling was used. ${ }^{10}$ Potential participants were culled at a public market during the peak hour of 5 p.m. Every tenth person who entered the market was approached to answer the questionnaire, and every tenth stall owner inside the market was approached to be a vendorrespondent. A quota of 10 respondents for consumers and vendors, respectively, was implemented for one day, then the same sampling for another four consecutive days was conducted until 100 participants were attained.

Most of the respondents were 31 years of age or older and had at least completed high school. Half of the consumers were female and 20 percent of vendors were male; 48 percent of the consumers and 72 percent of the vendors were married.

\section{Results and Discussion}

\section{Environmental Changes}

Figure 1 presents a post hoc analysis with Bonferroni method of the local environmental changes associated with implementation of the plasticban policy. A Likert scale was developed with 5 being "strongly agree" and 1 being "strongly disagree." The perception of consumers that the ordinance reduced plastic use had an average weighted mean of 4.58 , interpreted as strongly agree. This

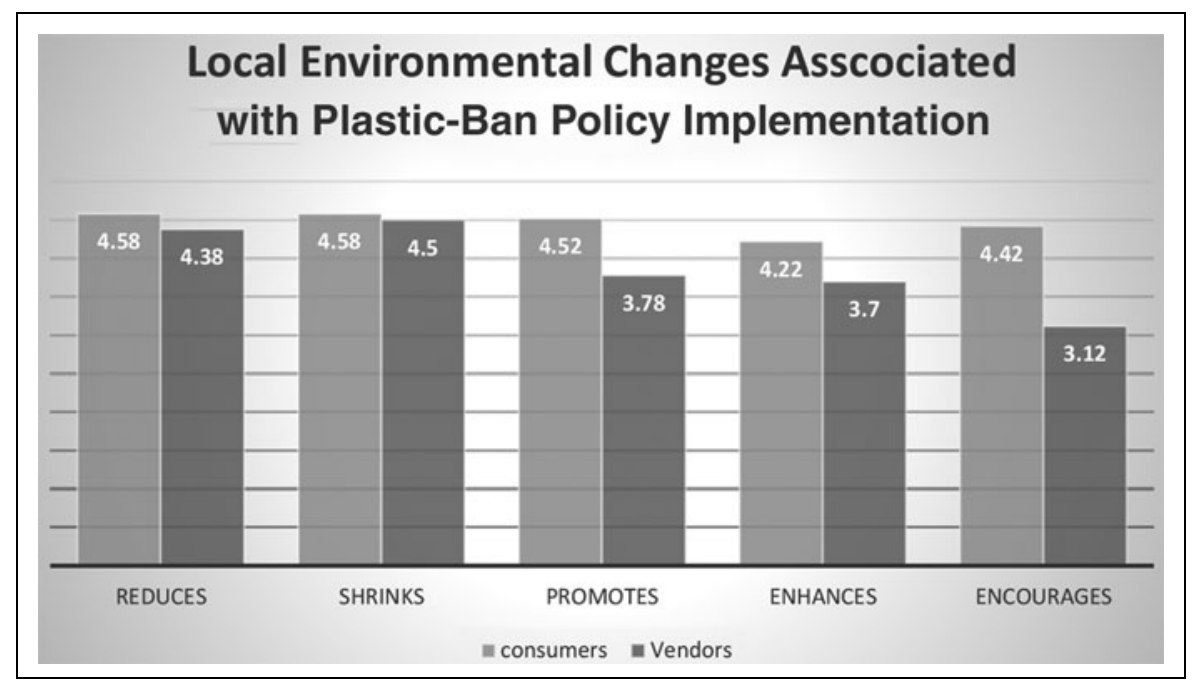

Figure 1. Local environmental changes associated with plastic-bag ban policy implementation 
means that consumers perceived that implementation of the plastic ordinance had an optimum effect on the environment. These findings were similar to Xiufeng, ${ }^{11}$ whose study concluded that public awareness on the effect of plastic bags on the environment can have minimal to dramatic effects on consumer behavior based on personal accounts, resources, and sustainability.

Vendors' perception of the evident shrinking of plastic litter had an average weighted mean of 4.50 , interpreted as strongly agree. The vendors perceived that the implementation of the plastic ordinance had moderate effects on the environment. This finding gained support from Aspin, ${ }^{12}$ who concluded that the Plastic Shopping Bags (Waste Avoidance) Act 2008 in South Australia had a significant benefit to the community because of its restriction of the supply of lightweight single-use plastic bags, reducing their number in the litter stream.

The qualitative description of strongly agree from both consumers and vendors suggests that all aspects of implementation of the ordinance exceeded expectations and the participants demonstrated a clear understanding of the ordinance. On the other hand, moderately-agree responses indicate that some aspects of the implementation approached expectations and that respondents demonstrated a clear understanding of the ordinance. Lastly, agree, as interpreted, suggests that the implementation met expectations, but the participants did not demonstrate significant personal learning or clear understanding of the ordinance. ${ }^{13}$

\section{Economic Changes}

Figure 2 presents a post hoc analysis with Bonferroni method of the local economic changes associated with plastic-ban policy implementation.

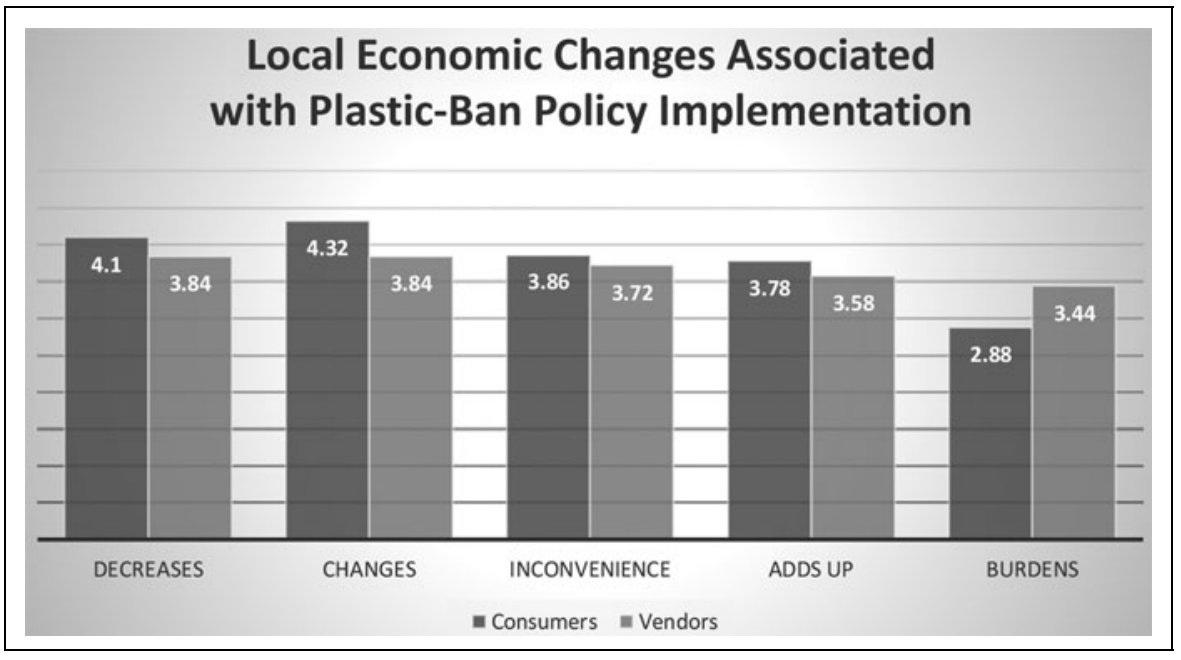

Figure 2. Local economic changes associated with plastic-bag ban policy implementation

Consumers' perception of changes in buying patterns as a result of the plastic ordinance in Dipolog City had an average weighted mean of 4.32 , interpreted as strongly agree. This means that consumers perceived that the plastic ordinance had moderately modified their buying patterns and increased their monetary savings. Moreover, the plastic-bag ban was not perceived to be an encumbrance. However, the plastic ordinance did impact buying activities, reportedly making them more inconvenient, but did not impact consumer buying despite making it more inconvenient and did not impact vendors' spending on marketing.

These findings are support by Krehbiel, ${ }^{14}$ who found that the bag ban prompted consumers to bring their own bag to the store more often. Over 95 percent of employees surveyed said they saw an increase in people bringing their own bags. Similarly, Villareal and Feigenbaum found that many stores also began offering reusable bags for purchase. ${ }^{15}$ They stressed that nearly half of these stores (48\%), lost money on reusable bags, but banning or taxing such bags reduced economic activity and increased unemployment.
Vendors' perception of the effects of implementation of the plastic ban on the economy was that it decreased money spent on marketing activities. The average weighted mean score of 3.84 was interpreted as moderately agree. Thus, plastic ordinances moderately decreased the marketing spending, changed buying patterns, inconvenienced shoppers, increased monetary savings, and placed an added burden on people's economic activities.

\section{Profile Variables: Environment}

\section{Location}

The data in Table 1 show the results of a Wilcoxon Signed Rank test, which was used to compare differences in perception about the effects of the plastic-bag ban on the environment, based on the address of the consumer. The level of significance at 0.05 is greater than the $p$-value of 0.03006 , which leads to the rejection of the null hypothesis. This indicates that there was a significant difference, and the probability is low that the difference is attributable to chance.

Residential location was found to be a factor in participants' perception about the effects of the ordinance. There were differences in perception 
Table 1. Test of Difference in the Perceived Environmental Changes Attributable to Implementation of the Plastic-Bag Ban

\begin{tabular}{|c|c|c|c|c|c|}
\hline Factors Compared & \multicolumn{5}{|c|}{ Perception of Environmental Change } \\
\hline Age & $\alpha=0.05$ & .07556 & 3.1579 & No significant difference & HO was accepted \\
\hline Marital Status & $\alpha=0.05$ & .78981 & 0.0711 & No significant difference & HO was accepted \\
\hline Gender & $\alpha=0.05$ & 1.00 & 0 & No significant difference & HO was accepted \\
\hline
\end{tabular}

HO: There is no significant difference in the perceived environmental changes attributable to implementation of the plastic-bag ban based on profile of participants.

between residents in one neighborhood compared to residents of another area. This implies that the participants' environment affected their perception. De Leon ${ }^{8}$ explained the concept of a people's culture as the "thing that makes them distinct and different from all other people." (p. 474) Cultures shape values, beliefs, and aspirations.

According to Segall and colleagues, ${ }^{16}$ while it is true that the basic process of perception is the same for all humankind, perceptions differ only because they reflect different perceptual, unconscious habits. Human perception is culturally influenced. Raudsepp conducted a survey that supports the hypothesis that environmental attitudes can influence consumer behavior where there is a difference between consumers based on their location. ${ }^{17}$ Sharholy et al. studied household plastic segregation practices in high income areas where residents had greater concern about waste disposal and on source separation for recycling. ${ }^{18}$

Regarding the age variable, the Wilcoxon Signed Rank was used to compare the existence of differences in the perception of implementation of the Dipolog plastic-ban ordinance on the environment. When analyzed, the level of significance at 0.05 is less than the $p$-value of 0.07556; thus, the null hypothesis was accepted. This means that the perception was the same in all age categories. This was similar to the findings of the Delhi-based study that suggested that both the youngsters and the elderly were more conscious or receptive to environmental health issues. ${ }^{19}$ But this runs counter to a study focusing on the role of socioeconomic factors, which found evidence that age is a significant driver of environmental attitudes and concern, with youth showing a greater concern. ${ }^{17,20}$

For civil status, the Wilcoxon Signed Rank test yielded a computed value of 0.0711 , which is significant at 0.05 level as it exceeded the $p$-value of 0.78981 . This leads to the acceptance of the null hypothesis, meaning that there is no significant difference in participants' marital status in their perception of the effects of the ordinance on the environment, and the probability is high that any differences occurred by chance.

\section{Education}

The data on educational attainment generated a level of significance at 0.05 , which is less than the $p$-value of 0.55818 . Thus, the null hypothesis was accepted, meaning that educational attainment was not a signifi- cant factor in the perceptual differences of the effect of the plastic ban on the environment. This implies that formal education of the participants had no effect on their perception about the ban on plastic bags in the environment. This conclusion was validated by Haider et $\mathrm{al}^{21}$ whose study showed that educational levels have no influence on the satisfaction level regarding government-mandated solid waste management practices.

While formal education may have no effect on people's perception about the ordinance, human behavior must always be understood in the context of a particular situation and the sociocultural environment. ${ }^{22}$ Environmental enlightenment can change people's attitudes toward waste generation and management. ${ }^{23} \mathrm{~A}$ program or campaign of public awareness and education that includes plastics in general can have positive implementation. ${ }^{24}$ The plasticban policy would then be successful if people are mindful as to its effect.

\section{Gender}

The data on gender show a Wilcoxon Signed Rank test of 0 . The level of significance at 0.05 is less than the $p$-value of 1 , which leads to acceptance of the null hypothesis. This means that there is no significant 
difference, and the probability is high that any difference in the gender variable between the perceived implementation of plastics and environment happened by chance. Most research finds slight evidence that women are more environmentally concerned $^{25}$ or possess stronger environmental attitudes than men ${ }^{26}$ (as cited by Pacatang et $\mathrm{al}^{20}{ }^{20}$ ). In a study by Davidson and Freudenburg ${ }^{27}$ (as cited by Felonneau and Becker $^{28}$ ), differences in environmental attitudes and behaviors are indeed caused by sociocultural norms and socialization; they vary according to culture. In a crosscultural study, Eisler et al. ${ }^{29}$ found significant gender differences in selfreported environmental behavior in their Japanese sample; however, no differences were found in Germany, Sweden, and the United States. Thus, although some gender differences were observed, these appear to be culture-dependent.

\section{Profile Variables: Economic}

\section{Location}

As shown in Table 2, there was a significant difference in perception about the effect of the plastic ordinance on the economy based on a resident's location. Wilcoxon Signed Rank test showed a $p$-value of 0.02274 , which is less than the significant level at 0.05 . Thus, the null hypothesis was rejected because there was a significant difference, and the probability is low that this difference was a chance occurrence. This implies that where the participants live to some extent shaped their perception.

A study conducted by the National Center for Policy Analysis in the U.S. found that a ban on plastic bags imposed on grocers and retailers negatively impacted sales in the ban area and increased sales in stores just outside the bag-ban region. The consumers who lived in an area where there was a bag ban, but near an area without one, often chose to shop at stores unaffected by the ban. ${ }^{30}$

\section{Age}

As shown in Table 2, when the data was analyzed based on age, the Wilcoxon Signed Rank test showed a mean of 3.4816, whose level of significance at 0.05 is less than the $p$ value of 0.6206 . Thus, the null hypothesis was accepted: there was no significant difference in perception about the effect of the plastic ordinance on the economy based on age of participants. Thus, age was not an influential factor for this variable.

\section{Marital status}

In the case of marital status, the Wilcoxon Signed Rank test of 0.5053 indicated a level of significance at
0.05 , which is less than the $p$-value of 0.4772 ; thus the null hypothesis was accepted. This means that there was no significant difference in perception about the effect of the plastic ordinance on the economy based on the marital status of the participant: The perception of married respondents was the same as the perception of single, widowed, or separated/ divorced participants. Thus marital status of participants did not influence their perception.

\section{Education}

The differences in educational attainment of the partipants had a Wilcoxon Signed Rank test of 0.4149, where the level of significance at 0.05 is less than the $p$-value of 0.51951 . Thus, the null hypothesis was accepted, indicating that educational attainment of the participants had no effect on their perception of the effect of the plastic ordinance on the economy.

\section{Gender}

For the gender variable, the Wilcoxon Signed Rank test showed 0.0079 with a $p$-value of 0.9292 , which is greater than the level of significance at 0.05 ; thus, the null hypothesis was accepted. This means that there was no significant difference in the perceived effects of the plastic ordinance on the economy

Table 2. Test of Difference in the Perceived Economic Changes Attributable to Implementation of the Plastic-Bag Ban

\begin{tabular}{|c|c|c|c|c|c|}
\hline \multirow[b]{2}{*}{ Factors Compared } & \multicolumn{5}{|c|}{ Perception of Economic Change } \\
\hline & $\alpha$ & $p$-value & Wilcoxon Signed Rank Test & Interpretation & Action/Decision \\
\hline Age & $\alpha=0.05$ & .06206 & 3.4816 & No significant difference & HO was accepted \\
\hline Marital Status & $\alpha=0.05$ & .4772 & 0.5053 & No significant difference & HO was accepted \\
\hline Gender & $\alpha=0.05$ & .9292 & 0.0079 & No significant difference & HO was accepted \\
\hline
\end{tabular}

HO: There is no significant difference in the perceived economic changes attributable to implementation of the plastic-bag ban based on profile of participants. 
when analyzed according to gender. The perception of female participants about the effects of the plastic ordinance on the economy was the same as that of male participants.

A study conducted by Adane and Muleta suggests that most people, regardless of their demographic background, favor the banning of production, distribution, and use of plastic products and are aware of the adverse effects of plastic bag waste. ${ }^{31}$ Customers can choose to avoid the charge of carryout paper bags by bringing reusable bags with them to the store or not using a bag for small purchases. This allows consumers to control the cost of the bags and adjust behaviors accordingly. ${ }^{32}$

While there is substantial literature available on the environmental impacts of plastic-bag bans, determining the economic impacts can be more challenging. Due in part to the number of variables affecting consumer behavior, it is difficult to quantify how manufacturers, retailers, and consumers may be affected. However, based on reports from jurisdictions with a plastic-bag ban in effect, there has been no substantial negative longterm impact to retailers, and no demonstrated migration of consumers to jurisdictions without a plastic ban. ${ }^{33}$

\section{Conclusion}

Based on the findings of this study, demographic profiles are not clearly associated with the trends in environmental changes, with the exception of location, which to some extent shaped perception.

Environmental changes help build public awareness about environmental protection and a sustainable society. However, environmental trends based on human action are understood in the context of a particular situation. Differences in environmental attitudes and behaviors are indeed related to sociocultural norms and socialization. Likewise, economic changes have brought an increase in people bringing their own bags and in stores offering reusable bags for purchase. Banning the production, distribution, and use of plastic products is important in understanding the adverse effects of its waste. Moreover, there has been no substantial, negative long-term impact on retailers, and no demonstrated migration of consumers to jurisdictions without plastic ban.

\section{Author Disclosure Statement}

No competing financial interests exist.

\section{References}

1. Whiting K. This is how long everyday plastic items last in the ocean. World Economic Forum, Davos, Switzerland, Nov. 2, 2018. https:// www.weforum.org/agenda/2018/11/ chart-of-the-day-this-is-how-longeveryday-plastic-items-last-in-theocean/ (last accessed 3/18/2020).

2. Bernstein M. Plastics in oceans decompose, release hazardous chemicals, surprising new study says. ACS Chemistry for Life. Aug. 16, 2009. https://www.acs.org/content/ acs/en/pressroom/newsreleases/ 2009/august/plastics-in-oceans-decom pose-release-hazardous-chemicals-sur prising-new-study-says.html (last accessed 3/18/2020).

3. Quick Facts. Population/Languages and Dialects. Dipolog Sports City, Dipolog City, Philippines. http://dipologcity.gov.ph/quick-facts/ (last accessed 3/06/2020).

4. Cadion HJ. Dipolog City implements 'No Plastic Day.' Mindanao
Pagadian Frontline, Frontline Mindanao News and Publication Network, May 11, 2014. https://pag adianfrontline.blogspot.com/2014/05/ dipolog-city-implements-no-plasticday.html (last accessed 3/06/2020). 5. Mindanao Daily News. Cagayan de Oro City, Philippines. https:// zamboanga.com $/ \mathrm{z} /$ index.php?title= Zamboanga_del_Norte_News_May_ 2014\#Dipolog_City_launches_.E2.80 .9Cno_plastic.E2.80.9D_ordinance (last accessed 3/19/2020).

6. DTI Philippines Cities and $\mathrm{Mu}-$ nicipalities Competitive Index. https:// cmci.dti.gov.ph/pages/rankings/ (Rank \#43 2019 \#CMCI2019) (last accessed 3/19/2020).

7. Carroll AB. Public awareness of environmental protection and corporate social responsibility. J Sustain Dev 2007;2(1).

8. De Leon HS. Textbook on the Philippine Constitution. Rex Bookstore, Inc. 856, Reyes Sr. St. Recto Avenue, Manila, Philippines. ISBN978-971-23-5104-4, 2008.

9. Thompson RC, Moore CJ, vom Saal FS, et al. Plastics, the environment and human health: Current consensus and future trends. Philos Trans R Soc Lond B Biol Sci 2009;364(1526):xx-xx.

10. Melero JL. Quota Sampling. Universitat Pompeu Fabra, TNS, 2011. https://www.upf.edu/documents/396 6940/3986764/Melero_seminar_3_ 2011.pdf/83c7b263-b07e-4343-be7fec2f07a5792d (last accessed 3/18/ 2020).

11. Xiufeng X. Study on the ban on free plastic bags in China. J Sustain Dev 2009;2(1):156-158.

12. Aspin M. Review of the Plastic Shopping Bags (Waste Avoidance) Act 2008 (Version 1.1.2009), 2012. https://www.greenindustries.sa.gov. au/_literature_165476/Review_of_ the_Plastic_Shopping_Bags_(Waste_ Avoidance)_Act_2008 (last accessed $3 / 16 / 2020)$. 
13. www.clayton.edu/Portals/538/ docs/D2LDocs/June2016/Rubrics.pdf (no longer available online)

14. Krehbiel R. New Survey: Plastic Bag Bans Big Success. Environment America, Dec. 19, 2012. https:// environmentamerica.org/news/wae/ new-survey-plastic-bag-bans-bigsuccess (last accessed 3/6/2020).

15. Villareal $P$, and Feigenbaum BA. Survey on the Economic Effects of Los Angeles County's Plastic Bag Ban. National Center for Policy Analysis, 2012. http://www.ncpath inktank.org/pdfs/st340.pdf (last accessed 3/16/2020).

16. Segall $\mathrm{MH}$, Campbell DT, and Herskovits MJ. The Influence of Culture on Visual Perception. BobbsMerrill, Indianapolis/New York, 1966. 17. Raudsepp M. Some sociodemographic and socio-psychological predictors of environmentalism. TRAMES 2001;5(4):355-367.

18. Sharholy M, Ahmad K, Mahmood G, et al. Municipal solid waste management in Indian cities: A review. Waste Manag 2008;28(2):459467.

19. Gupta K, and Somanathan R. Consumer response to incentives to reduce plastic bag use: Evidence from a filed experiment in urban India (working paper). Delhi, School of Economics, 2011.

20. Pacatang DHQ. Miputak Creek rehabilitation and its perceived benefits to its residents. Asian J Soc Sci Humanit 2016;5(1):168-182.

21. Haider A, Amber A, Shahid A, et al. Knowledge, perception and attitude of common people towards solid waste management-A case study of Lahore, Pakistan. Int Res J
Environ Sci 2015;4(3):100-107. http://www.isca.me/IJENS/Archive/ v4/i3/14.ISCA-IRJEvS-2015-002.php (last accessed 3/06/2020).

22. Keren JA, Zimmer MR, and Golden LL. Object relations theory: Male and female differences in visual information processing. In Wallendorf M, and Anderson P (eds.), Advances in Consumer Research, vol. 14. Association for Consumer Research, Provo, UT, 1987, pp. 83-87.

23. Afangideh AI. Attitude of urban dwellers to waste disposal and management in Calabar, Nigeria. Eur J Sustain Dev 2012;1(1):22-34.

24. Mudgal S, and Lyons L. Plastic Waste in the Environment, Final Report. BIO Intelligence Service, in coordination with AEA Technology and Institute for European Environmental Policy. European Commission DG ENV, 2011.

25. Jones R, and Dunlap R. The social bases of environmental concern: Have they changed over time? Rural Sociol 1992;57(1):28-47.

26. Foster $\mathrm{RH}$, and McBeth MK. Urban-Rural influences in US environmental and economic development policy. J Rural Stud 1996; 12(4):387-397.

27. Davidson DJ, and Freudenburg WR. Gender and Environmental Risk Concerns: A Review and Analysis of Available Research. Environ Behav 1996;28(3):302-339. https:// journals.sagepub.com/doi/abs/10.1177/ 0013916596283003\%20\%20\%20\%20 (last accessed 3/19/2020).

28. Felonneau M-L, and Becker M. Pro-environmental attitudes and behavior: Revealing perceived social desirability. Revue Internationale de
Psychologie Sociale 2008;4(21): 25-53.

29. Eisler AD, Eisler $H$, and Yoshida M. Perception of human ecology: Cross cultural and gender comparisons. J Environ Psychol 2008;23 (1):89-101.

30. Caliendo $\mathrm{H}$. The Economic Effect of Plastic Bag Bans. Plastics Today, Feb. 6, 2013. https://www. plasticstoday.com/content/economiceffect-plastic-bag-bans/35843076718 443 (last accessed 3/11/2020).

31. Adane L, and Muleta D. Survey on the usage of plastic bags, their disposal and adverse impacts on environment: A case study in Jimma City, Southwestern Ethiopia. J Toxicol Environ Health Sci 2011; 3(8): 234-248.

32. AECOM. Proposed Ban on Plastic Carryout Bags in Los Angeles County. Project Report: Economic Impact Analysis for Sapphos Environmental, Inc., Pasadena, CA, 2010.

33. Equinox Center. Plastic Bag Bans: Analysis of Economic and Environmental Impacts, 2013. https://energycenter.org/sites/default/ files/Plastic-Bag-Ban-Web-Version10-22-13-CK.pdf (last accessed 3/ $11 / 2020)$.

Address correspondence to: David Harold Q. Pacatang Jose Rizal Memorial State University College of Criminology

Turno, Dipolog City

Zamboanga del Norte 7100 Philippines

E-mail: davidhq_pacatang@yahoo. com 